\title{
Proceeding
}

Supplementary Issue: Spring Conferences of Sports Science. Costa Blanca Sports Science Events, 14-15 June 2019. Alicante, Spain.

\section{Autonomic modulation and association with the performance in a jump test in university Colombian players of rugby seven}

\author{
LUIS JAVIER TAFUR TASCÓN1', MOISES ARTURO CABRERA HERNANDEZ1', LUIS FERNANDO NEISA \\ HERRERA ${ }^{2}$, SERGIO ANDRÉS GARCÍA-CORZO ${ }^{1} \mathrm{~J}$, CAMILO HERNESTO POVEA COMBARIZA ${ }^{3}$, \\ CARMEN XIMENA TEJADA ROJAS ${ }^{1}$
}

${ }^{1}$ Area of Sports Medicine and Special Test (MEDES), Faculty of Education and Sport Sciences, University Institution National Sports School, Cali, Colombia

${ }^{2}$ Faculty of Medicine, University El Bosque, Bogotá, Colombia

${ }^{3}$ Faculty of Medicine, National University, Bogotá, Colombia

\begin{abstract}
It has been observed that training influences modulation of autonomic activity and it can be represented in Heart Rate Variability (HRV). Evaluation of HRV can be useful to obtain information about the internal load to which an individual is being subjected, in order to adjust training loads, either with the aim of increasing sports performance or to prescribe an adequate load to improve specific qualities for the sport. Therefore, the purpose of this study was to evaluate the behaviour of autonomic modulation and its association with performance in a jump test, in university players of Rugby Seven. 11 men who belonged to the university team (age $23.63 \pm 2.15$ years; weight $84.43 \pm 10.44 \mathrm{~kg}$; height $1.80 \pm 0.04 \mathrm{~m}$ ), national champion of Colombia in the year 2016 of Rugby Seven, were volunteers for the research. Abalakov jump, CMJ, SJ and DJ were evaluated. We evaluated the behaviour of the autonomic modulation, in controlled resting situation, controlled ventilation, orthostatism, exercise and recovery. Main result of this study was evidence that sympathetic modulation can be reflected in the development of force to execute a jump; because association found between the low frequency component of heart rate variability $\left(2238.364 \pm 1381.531 \mathrm{~ms}^{2} / \mathrm{Hz}\right)$ and performance in DJ $(22.3 \pm 3.66 \mathrm{~cm})(r=0.65, p=0.029)$. Keywords: Colombian; Rugby seven; Autonomic modulation; Jump test.

\section{Cite this article as:}

Tafur, L.J., Cabrera, M.A., Neisa, L.F., García-Corzo, S.A., Povea, C.H., \& Tejada, C.X. (2019). Autonomic modulation and association with the performance in a jump test in university Colombian players of rugby seven. Journal of Human Sport and Exercise, 14(4proc), S1102-S1111. doi:https://doi.org/10.14198/ihse.2019.14.Proc4.74

Corresponding author. Area of Sports Medicine and Special Test (MEDES), Faculty of Education and Sport Sciences, Institución Universitaria Escuela Nacional del Deporte, Cali, Valle del Cauca, Colombia. http://orcid.org/0000-0003-0678-7468 E-mail: sergio.garcia@endeporte.edu.co

Supplementary Issue: Spring Conferences of Sports Science. Costa Blanca Sports Science Events, 14-15 June 2019. Alicante, Spain.

JOURNAL OF HUMAN SPORT \& EXERCISE ISSN 1988-5202

(c) Faculty of Education. University of Alicante doi:10.14198/jhse.2019.14.Proc4.74
\end{abstract}




\section{INTRODUCTION}

Rugby Sevens is a team sport in which intermittent activities (high-intensity running, accelerations, and decelerations, among others) and constant collisions are always present (Henderson et al., 2018).

Along a match, a player may run about $1500 \mathrm{~m}$, of which two thirds are completed at an intensity higher than $85 \%$ of the maximum heart rate ( $\left.H R_{\max }\right)$ and $9 \%$ is completed at the highest speed (Suarez et al., 2012). This implies being subject to great physiological stress (Elloumi et al., 2012), thus reaching loads similar to those observed in high-intensity anaerobic training (Takahashi et al., 2007). Likewise, it is common to see tournaments lasting from 2 to 3 days, in which each team plays a total of 5 to 6 matches, playing up to 3 times per day (Henderson et al., 2018). A match consists of two halves of 7 minutes each, with a 2-minute resting period between the two halves (Higham et al., 2012). These specific activities and their intensity can lead to a cumulative load that may cause a decrease in Vertical Jump (VJ), Drop Jump (DJ), Squat Jump (SJ), and Countermovement Jump test (CMJ) performance (Twist and Highton, 2013), and can even lead to a CMJ performance reduction up to 60 hours after a tournament (West et al., 2014; Twist et al., 2012).

The autonomic nervous system (ANS) is an important component of the nervous system, which comprises a complex neuron web and nervous pathways controlling the function of different organs and systems through its three efferent components (sympathetic, parasympathetic, and enteric) (Camm et al., 1996; Povea, 2006; Low, 2001). It is possible to carry out a non-invasive evaluation of the ANS by studying Heart Rate Variability $(\mathrm{HRV})$, which is defined as the physiological variation of the time between two heart beats, a consequence of the modulation exerted by the ANS on the heart (Camm et al., 1996; Povea, 2006). HRV can be measured by using the Frequency Domain Method, consisting of the analysis of the oscillations of heart rate (Camm et al., 1996; Povea, 2006) and the spectral analysis of high-frequency component (HF), which includes wave frequencies higher than $0.15 \mathrm{~Hz}$ and is considered an indicator of parasympathetic activity (Camm et al., 1996; Povea, 2006); the low-frequency component (LF), or waves between 0.05 y $0.15 \mathrm{~Hz}$, which is considered to be a mixed indicator reflecting both the modulation of the sympathetic and the parasympathetic systems (Camm et al., 1996; Povea, 2006). However, the LF/HF ratio evaluates the balance between the two components of the ANS and can be considered an indicator of the sympathetic activity (Camm et al., 1996; Povea, 2006). Therefore, HRV reflects the behaviour of the ANS, by evaluating the modulation exerted by the sympathetic and the parasympathetic nervous systems on the necessary physiological adaptations under different conditions such as physical exercise (Camm et al., 1996; Povea, 2006).

This modulation of the ANS (or autonomic modulation) plays a key role in the mediation of cardiovascular adjustments such as the increase of cardiac output, a consequence of both the increase of heart rate and the volume ejected by the left ventricle which are required to meet the metabolic demands of the muscle during exercise, thus being of much importance in sports performance (Morales et al., 2014; Fisher et al., 2011). For instance, it has been observed that during dynamic exercise (like jumping), the behaviour of HRV tends to be lower than in static exercise, which is due mainly to vagal disengagement and an increase of sympathetic activity (Goldsmith et al., 2000; lellamo et al.,2002). After exercise, the increase of parasympathetic activity shows up in the reactivation of this component of the vegetative nervous system along the recovery phase (Buchheit et al., 2008; Goldberger et al., 2006).

The influence of training on the modulation of autonomic activity has been documented, which allows for better control during exercise, and is reflected on HRV (Fisher et al., 2013; Fisher, 2014). This autonomic modulation is also believed to be influenced by previous physical loads, or by the loads following a rugby match in elite juvenile players (Edmonds et al., 2013), thus causing reduction in neuromuscular function, 
similar to the one observed in performance during (VJ, DJ, SJ, CMJ) jump tests (Twist and Highton, 2013). The assessment of HRV can prove useful in obtaining information about the internal load an individual is being subject, so that training loads can be adjusted with the purpose of increasing sports performance or prescribing an moderate load to seek improvement of specific sports qualities (Fisher et al., 2011; Borresen and Lambert, 2008). To date, there exists no study dealing with the description of the behaviour of autonomic modulation in university Rugby Sevens players which evaluate the association between autonomic modulation, measured under controlled conditions, and performance in different jump tests. Therefore, the purpose of this study was to evaluate the behaviour of autonomic modulation at rest, controlled ventilation, orthostatism, exercise, and recovery conditions and its association with performance on a jump test, in university Rugby Sevens players.

\section{METHOD}

\section{Subjects}

Eleven male players of the university team, the 2016 Colombian National Rugby Sevens Champion team, volunteered for this study. All players had been on the university team for at least two years and were ongoing competitors. Each subject was asked not to train, not drink any alcoholic beverages, and not use any sympathetic mimetic substance 24 hours prior to test administration. The study was carried out as part of the training program, under the supervision of the coaches. Subjects were informed verbally and in writing about possible risks and benefits, and all signed an informed consent. This study was carried out under the codes of ethics of the Declaration of Helsinki and was approved by the Institutional Ethics Committee.

\section{Methodology}

HRV

The HRV Test protocol used in this study was based on Povea, C. (2006), an explanation of which is given below.

Registration lasted 19 minutes. The test started in a decubitus supine position on a stretcher, for 7 minutes (Phase 1). Next, the player was asked to complete a controlled ventilation at 10 cycle per minute, for 1 minute (Phase 2). Then, a 1-minute, 12-cycle controlled ventilation was completed. 3) Immediately after completing Phase 2, position was changed from decubitus supine to bipedestation (Phase 4). The orthostatism phase lasted 4:15 minutes, keeping the position in phase 4 (Phase 5). After the orthostatism period, the subject completed one series of 30 squats, for 45 seconds (Phase 6). Finally, the subject went back to the decubitus supine position, for 5 minutes (Phase 7) (Povea, 2006).

\section{Jump Test}

The jumps performed were Abalakov, CMJ, SJ, and DJ. The jumping technique is described by Bosco et al., (1983) (Bosco, C., \& Riu, 1994; Bosco et al., 1993).

\section{Procedures}

The evaluations were carried out at the Physiology Laboratory of Institutcion Universitaria Escuela Nacional del Deporte. The day before test administration, a clinical evaluation was conducted by a physician specialized in sports medicine, in order to assess the physical condition of the subjects who were asked to be at the testing site at least an hour after their last meal.

The anthropometric variables measured included age, body mass, and height. The body-mass index (BMI) was calculated. 
The weight (Fitscan BC-585F ${ }^{\circledR}$ ) and size (SECA $213^{\circledR}$ ) were measured between 7:00 am and 7:30 am, on the day heart rate variability and the jump test were measured. Between 7:30 am and 8:30 am, Interval R-R was recorded from up to 4 athletes simultaneously, using cardio-frequency meters POLAR RS $800 C X^{\circledR}$, at $20^{\circ} \mathrm{C}$ room temperature, in dark and soundproof rooms.

After completing the autonomic function test, each subject completed a five-minute warming up session, using a cyclo ergometer (Monark Ergomedic $828 \mathrm{E}^{\circledR}$ ) at a comfortable cadence (70-80 rpm), without any external resistance. Then, the Jump Test was performed on an Axon Platform (Axón Jump ${ }^{\circledR}$ ).

For the analysis of the jumps, the best of the three jumps was considered, taking into account the height measured in centimetres. The execution order of the jumps was always the same one, Abalakov, CMJ, SJ, and DJ, the last of which was attempted from a 40-cm height (Bosco, C., \& Riu, 1994; Bosco et al., 1993).

Data for HRV was analysed using software Kubios $H R{ }^{\circledR}$ version 3.0.2. The Frequency Domain Method was used to measure HRV in each test phase. Deltas in bands HF ( $\triangle \mathrm{HF})$ and $L F(\Delta \mathrm{LF})$ were calculated, as well as the ratio $\mathrm{LF}: \mathrm{HF}(\Delta \mathrm{LF} / \mathrm{HF})$ and $H R(\Delta \mathrm{HR})$. This was done by subtracting the value of the previous phase from the value obtained in each phase (except the first phase). The body-mass index was calculated using spectral bands LF (LF.kg-1) and HF (HF.kg-1). The mean HR in the first minute of the recovery phase and the HR mean of the other phases were measured. In addition, the HRmax was recorded for postural change and 2 minutes after the orthostatism phase, as they reflect the physiological response to orthostatic stress in the absence of parasympathetic activity and an increase of sympathetic activity [10].

\section{Statistical Analysis}

The statistical analysis was carried out by using software SPSS $24.0^{\circledR}$ for Windows, Chicago. IL, USA. Shapiro-Wilk Test was used to verify normality. The descriptive analysis is expressed as mean $\pm \mathrm{SD}$. Pearson correlation coefficient was used for the association analysis between the variables of the jump test, the HR, and the variables for HRV. Statistical significance of $-p<0.05$ was considered for all the tests.

\section{RESULTS}

Table 1 depicts the general characteristics of the population.

Table 1. Descriptive Variables for Rugby Sevens players

\begin{tabular}{ll}
\hline Variables $(\mathbf{n}=11)$ & Mean \pm SD \\
\hline Age (years) & $23.63 \pm 2.15$ \\
Body mass $(\mathrm{kg})$ & $84.43 \pm 10.44$ \\
Height $(\mathrm{m})$ & $1.80 \pm 0.04$ \\
BMl $\left(\right.$ Kg. $\left.\mathrm{m}^{-2}\right)$ & $26.24 \pm 3.17$ \\
\hline
\end{tabular}

Table 2 depicts the behaviour of the variables in the Autonomic Modulation Test. 
Table 2. Results for the HRV Test

\begin{tabular}{llcccc}
\hline \multirow{2}{*}{ Phases } & \multicolumn{4}{c}{ Variables (Mean $\pm \mathrm{SD})$} \\
\cline { 2 - 5 } & $\mathrm{HR}(\mathrm{lpm})$ & $\mathrm{LF}\left(\mathrm{ms}^{2} / \mathrm{Hz}\right)$ & $\mathrm{HF}\left(\mathrm{ms}^{2} / \mathrm{Hz}\right)$ & $\mathrm{LF} / \mathrm{HF}\left(\mathrm{ms}^{2} / \mathrm{Hz}\right)$ \\
\hline Phase 1 & Decubitus supine & $58.727 \pm 7.058$ & $2209.909 \pm 3306.580$ & $2117.181 \pm 2512.871$ & $1.067 \pm 0.722$ \\
Phase 2 & Controlled ventilation 10CPM & $64.909 \pm 7.828$ & $1163.182 \pm 1139.694$ & $4867.818 \pm 2684.831$ & $0.318 \pm 0.307$ \\
Phase 3 & Controlled ventilation 12CPM & $65.818 \pm 6.968$ & $1501.727 \pm 2243.864$ & $4399.909 \pm 2324.059$ & $0.273 \pm 0.346$ \\
Phase 4 & Postural change & $90.545 \pm 12.933^{*}$ & $2238.364 \pm 1381.531$ & $944.818 \pm 510.915$ & $2.640 \pm 1.693$ \\
Phase 5 & Orthostatism (2nd minute) & $82.818 \pm 16.750^{*}$ & $2581.909 \pm 1320.074$ & $756.909 \pm 568.749$ & $4.071 \pm 2.199$ \\
Phase 6 & Exercise & $109.636 \pm 11.298$ & $77.182 \pm 65.819$ & $60.909 \pm 112.249$ & $5.235 \pm 5.720$ \\
Phase 7 & Recovery (1st minute) & $82.727 \pm 8.319$ & $2719.545 \pm 2267.757$ & $2917.818 \pm 1760.930$ & $1.161 \pm 1.260$ \\
\hline \multicolumn{4}{c}{${ }^{*}=$ Mean of HRmax } \\
\multicolumn{5}{c}{ CPM $=$ Cycles per minute }
\end{tabular}

Table 3 depicts the results of the calculation of the body-mass index using LF and HF spectral bands.

Table 3. Results of the calculation of the body-mass index using LF and HF spectral bands

\begin{tabular}{llcc}
\multirow{2}{*}{ Phases } & & \multicolumn{2}{c}{ Variables (Mean \pm SD) } \\
\cline { 3 - 4 } & & $\mathrm{LF} . \mathrm{kg}^{-1}\left(\mathrm{~ms}^{2} / \mathrm{Hz} . \mathrm{kg}^{-1}\right)$ & $\mathrm{HF} . \mathrm{kg}^{-1}\left(\mathrm{~ms}^{2} / \mathrm{Hz}_{\mathrm{kg}}-1\right)$ \\
\hline Phase 1 & Decubitus supine & $29.073 \pm 49.612$ & $27.422 \pm 37.175$ \\
Phase 2 & Controlled Ventilation 1 & $14.681 \pm 16.390$ & $60.706 \pm 37.665$ \\
Phase 3 & Controlled ventilation 2 & $18.944 \pm 28.616$ & $55.344 \pm 35.290$ \\
Phase 4 & Postural change & $26.580 \pm 15.880$ & $11.382 \pm 6.399$ \\
Phase 5 & Orthostatism (2nd minute) & $30.309 \pm 14.761$ & $9.227 \pm 7.953$ \\
Phase 6 & Exercise & $0.928 \pm 0.753$ & $0.712 \pm 1.257$ \\
Phase 7 & Recovery (1st minute) & $34.134 \pm 33.268$ & $35.988 \pm 23.185$ \\
\hline
\end{tabular}

Deltas for HF and LF bands, for the LF:HF ratio, and HR ARE depicted in la Table 4.

Table 4. Deltas for HF, LF, HR, and LF:HF ratio

\begin{tabular}{|c|c|c|c|c|c|}
\hline \multirow{2}{*}{ Phases } & & \multicolumn{4}{|c|}{ Variables (Mean \pm SD) } \\
\hline & & $\Delta \mathrm{LF}\left(\mathrm{ms}^{2} / \mathrm{Hz}\right)$ & $\Delta \mathrm{HF}\left(\mathrm{ms}^{2} \mathrm{~Hz}\right)$ & $\Delta \mathrm{LF} / \mathrm{HF}$ & $\Delta \mathrm{HR}(\mathrm{Ipm})$ \\
\hline $\begin{array}{l}\text { Phase } 2 \\
\text { Phase } 1\end{array}$ & $\begin{array}{l}\text { Controlled ventilation } 1 \\
\text { Decubitus supine }\end{array}$ & $-1046.727 \pm 2492.099$ & $2750.636 \pm 2784.282$ & $-0.749 \pm 0.739$ & $6.182 \pm 4.687$ \\
\hline $\begin{array}{l}\text { Phase } 3 \\
\text { Phase } 2\end{array}$ & $\begin{array}{l}\text { Controlled ventilation } 2 \\
\text { Controlled Ventilation } 1\end{array}$ & $338.545 \pm 2020.778$ & $-467.909 \pm 2631.147$ & $-0.045 \pm 0.098$ & $0.909 \pm 3.177$ \\
\hline $\begin{array}{l}\text { Phase } 4 \\
\text { Phase } 3\end{array}$ & $\begin{array}{l}\text { Postural Change } \\
\text { Controlled ventilation } 2\end{array}$ & $736.636 \pm 2255.802$ & $-3455.091 \pm 2173.276$ & $2.366 \pm 1.771$ & $24.727 \pm 10.603$ \\
\hline $\begin{array}{l}\text { Phase } 5 \\
\text { Phase } 4\end{array}$ & $\begin{array}{l}\text { Orthostatism } \\
\text { Postural Cambio }\end{array}$ & $343.545 \pm 1539.694$ & $-187.909 \pm 681.262$ & $1.431 \pm 2.698$ & $-7.727 \pm 5.711^{*}$ \\
\hline $\begin{array}{l}\text { Phase } 6 \\
\text { Phase } 5\end{array}$ & $\begin{array}{l}\text { Exercise } \\
\text { Orthostatism }\end{array}$ & $-2504.727 \pm 1328.693$ & $-696.000 \pm 610.686$ & $1.165 \pm 6.460$ & $26.818 \pm 10.843$ \\
\hline $\begin{array}{l}\text { Phase } 7 \\
\text { Phase } 6\end{array}$ & $\begin{array}{l}\text { Recovery } \\
\text { Exercise }\end{array}$ & $2642.364 \pm 2292.545)$ & $2856.909 \pm 1752.404$ & $-4.075 \pm 5.957$ & $-26.909 \pm 7.436$ \\
\hline
\end{tabular}

Table 5 depicts the results of the jump test. 
Table 5. Results of the jump test

\begin{tabular}{lc}
\hline Type of jump & Height of best jump in cm (Mean \pm SD) \\
\hline Abalakov & $43.8 \pm 5.53$ \\
CMJ & $39 \pm 5.17$ \\
SJ & $33 \pm 5.69$ \\
DJ & $22.3 \pm 3.66$ \\
\hline
\end{tabular}

CMJ = Countermovement Jump Test; SJ = Squat Jump; DJ = Drop Jump.

Table 6 summarizes the most important results of the correlations between the variables of the jump test, the $H R$, and the variables of the HRV.

Table 6. Correlations between the variables of the jump test, the HR, and the variables of the jump test, the $\mathrm{HR}$, and the HRV variables of the HRV

\begin{tabular}{lcll}
\hline & Variables & $r$ & $p$ \\
\hline DJ & $\mathrm{LF}$ in Phase 4 ( postural change) & 0.65 & 0.029 \\
$\mathrm{DJ}$ & $\mathrm{LF} . \mathrm{Kg}^{-1}$ in phase 4 (postural change) & 0.75 & 0.007 \\
$\mathrm{HR}_{\max }$ Phase 4 (postural change) & $\begin{array}{l}\mathrm{L} \text { F between phase 5 and 4 } \\
\text { (orthostatism and postural changes) }\end{array}$ & 0.65 & 0.028 \\
$\Delta \mathrm{FC}_{\max }$ between phase 5 and 4 & $\begin{array}{l}\text { (orth between phase 5 and 4 } \\
\text { (orthostatism and postural changes) }\end{array}$ & 0.86 & 0.001 \\
\hline & $D J=$ Drop Jump & &
\end{tabular}

\section{DISCUSSION}

This is one of the first studies focusing on the correlation between the autonomic function test at rest and the jump tests in university Rugby Sevens players at a competition phase.

The main finding of this study was evidence that sympathetic modulation can reflect on the development of the strength necessary to execute a jump. This may be explained by the association between the low frequency component of heart rate variability (LF) and the performance in DJ.

\section{Body mass as autonomic conditioner}

Anthropometry can be used as a prediction tool of sports performance in rugby, since it has been observed that the muscle component positively influences performance in strength and speed tests (Rodríguez et al., 2008). As a result of the Somatometry, Rodríguez et al. (2008) found a general tendency towards mesomorphism, characterized by robust muscle mass, common in sports demanding high strength development as in Rugby Sevens. They reported a correlation of $(r=0.72)$ between performance $(\mathrm{cm})$ in CMJ and SJ, and muscle mass (Rodríguez et al., 2008).

In our study, the low frequency spectral component of body mass (LF.Kg-1) in postural change was positively correlated with the height obtained $(\mathrm{cm})$ in DJ $(r=0.75 ; p=0.007)$, similar to what was observed by Rodríguez et al. (2008). In addition, these values of the spectral component LF. Kg-1 showed a better correlation with DJ, when compared with the absolute values (non-weight related). This suggests that body mass is a conditioner of the sympathetic response observed in postural change and is a determinant of the manifestation of reactive elastic strength in elite university Rugby Sevens players. 


\section{Cardiac autonomic function in postural changes and its association with DJ}

Muscle strength is an indispensable physical quality in the development of sports activities, which is defined as the muscle capacity opposing resistance (Ravé et al., 2010). However, this concept has been extended, so currently, strength not only refers to an individual component of the osteomuscular system, but also to a neuromuscular quality. This is important because if the nervous system is not taken as the controlling centre of muscle activities, the precision, speed, and quality of muscle contraction would not be the adequate ones (Ravé et al., 2010).

The ANS plays an important role in reflecting the intensity of muscle work shown as cardiovascular response. For instance, Matsukawa et al. (1994) and Murata \& Matsukawa (2001) carried out selective stimulation by passive stretching in animal lower limbs under anaesthesia conditions. They found sympathetic activation during stretching and muscle electrical activation caused by an increase of heart rate and a decrease of this in absence of stretching (Murata and Matsukawa, 2001; Matsukawa, 1994). Likewise, Teixeira et al. (2017) found that sympathetic cardiac response during exercise is influenced by changes in body position and suggest that muscle mecanoreflex, metaboreflex, and cardiopulmonary baroreflex have a synergetic influence on neuronal control of cardiovascular function in humans (Teixeira et al., 2017). Gladwell and Coote (2002) also conducted sustained passive sural triceps stretching with a group of 20 patients and found an increase of 5-6 beats in cardiac frequency during stretching and a decrease at rest (Gladwell and Coote., 2002). Therefore, muscle mecanoreflex is activated mainly at the beginning of muscle contraction at the time of distortion of the mechanoreceptors, stimulating mainly myelinated afferent fibres type III, that generally respond to mechanical stimuli (Gladwell and Coote., 2002). Afferent fibres type III trigger impulses from the onset of the contraction and are activated before the metaboreceptors, which are chemically sensitive during exercise (changes in $\mathrm{pH}$, lactate, $\mathrm{iP}_{-}, \mathrm{H}^{+}$) and respond to changes in the degree of intensity of the contraction by sending impulses through afferent pathways type IV (Gladwell and Coote., 2002). Type III fibres have the potential to contribute to autonomic cardiac responses during early exercise (Gladwell and Coote., 2002). This would explain the strong association observed in this study between the LF component in orthostatic postural change and height in DJ which requires concentric contraction preceded by brief eccentric activation, thus generating a relative activation of elastic energy which later activates motor units via reflex (explosive elastic reflex). This leads to the manifestation of reactive elastic strength produced in this jump, which may be probably and partially due to an increase in the sympathetic activity reflected on an increase of the LF spectral component (Teixeira et al., 2017; Gladwell and Coote., 2002).

The degree of correlation between the height obtained in DJ and the LF spectral component in postural change is similar to the one reported by Morales et al. (2014) who found significant correlation between the mean height in 5 vertical jumps with sympathetic modulation $(r=0.7942, p=0.01)$ and a moderate correlation between the increase of the fatigue index in 60 seconds of vertical jumps and the mean height in 5 vertical jumps ( $r=0.7206, p=0.04 ; r=0.79442 ; p=0.01$ respectively), with high modulation of the vegetative ratio (LF/HF) in the recovery phase (Morales et al., 2014). The researchers concluded that the high-intensity intermittent loads show highly significant responses of sympathetic modulation in connection with the manifestation of explosive strength. They also concluded that the height of vertical jumps has a significant correlation with autonomic modulation at rest, where subjects with a predominance of the low frequency component (LF) during the recovery phase performed badly in CMJ (Morales et al., 2014). This can be explained because of the need to meet the metabolic demands of skeletal muscles to generate the maximum strength for the execution of vertical jumps, an action dependent of the activation and reactivation of the autonomic nervous system (Morales et al., 2014). 
Finally, our study found positive correlation between LF in phase 4 (postural change) and performance in DJ, together with a decrease of the HF spectral component during postural change, and greater action of the HF spectral component at rest. Although in our study the valuation of HRV was measured previously to the jump, this can still be compared with the findings of Teixeira et al. (2017) who postulate a greater autonomic sympathetic contribution in lower limb exercise as a robust and trustful mechanism (muscle contraction) which stimulates muscle metaboreflex and mecanoreflex, resulting in modifications or responses of the autonomic activity and, consequently, of the cardiac frequency assessed (Teixeira et al. (2017).

\section{CONCLUSIONS}

Sympathetic activity, which was evaluated based on the LF spectral component and the orthostatic postural change, show significant correlation with the development of reactive strength evaluated in a DJ test and is positively influenced by body mass in university Rugby Sevens players.

Our findings suggest that the calculation of the strength for lower limbs through the jump test may be influenced by sympathetic modulation. The search for easy-to-obtain indicators (HR at rest, with postural change, etc.) which may somehow express sympathetic activity, is one of the main findings of our study, together with the use of the differences in the LF spectral component and their association with HR. Likewise, the correlation between DJ and the behaviour of the LF spectral component in phase 4 (postural change) suggest an association between sympathetic autonomic modulation and performance in activities involving reactive elastic strength, as in the case of DJ.

It is suggested that future studies consider the evaluation of the spectral components of HRV not only under controlled conditions, but also in jump execution, exercise, and game activities.

\section{ACKNOWLEDGMENTS}

We would like to thank all the participants in the study for their committed contribution. The authors would also like to thank the Faculty of Education and Sports Sciences at Institución Universitaria Escuela Nacional del Deporte (director José Fernando Arroyo Valencia and professor Sandra Parra) for their valuable support.

The experiments carried out in this study comply with the laws in force in the country in which they were made.

\section{REFERENCES}

Borresen, J., \& Lambert, M. I. (2008). Autonomic control of heart rate during and after exercise. Sports Med, 38(8), 633-646.

Bosco, C., \& Riu, J. M. P. (1994). La valoración de la fuerza con el test de Bosco (pp. 35-138). Barcelona: Paidotribo.

Bosco, C., Mognoni, P., \& Luhtanen, P. (1983). Relationship between isokinetic performance and ballistic movement. Eur J Appl Physiol O, 51(3), 357-364. https://doi.org/10.1007/bf00429072

Buchheit, M., Millet, G. P., Parisy, A., Pourchez, S., Laursen, P. B., \& Ahmaidi, S. (2008). Supramaximal training and postexercise parasympathetic reactivation in adolescents. Med Sci Sport Exer, 40(2), 362-371. https://doi.org/10.1249/mss.0b013e31815aa2ee

Camm, A. J., Malik, M., Bigger, J. T., Breithardt, G., Cerutti, S., Cohen, R. J., ... \& Lombardi, F. (1996). Heart rate variability: standards of measurement, physiological interpretation and clinical use. Task 
Force of the European Society of Cardiology and the North American Society of Pacing and Electrophysiology. https://doi.org/10.1111/j.1542-474x.1996.tb00275.x

Edmonds, R., Sinclair, W. and Leicht, A. (2013). Effect of a Training Week on Heart Rate Variability in Elite Youth Rugby League Players. Int J Sports Med, 34(12), pp.1087-1092. https://doi.org/10.1055/s-0033-1333720

Elloumi, M., Makni, E., Moalla, W., Bouaziz, T., Tabka, Z., Lac, G., \& Chamari, K. (2012). Monitoring training load and fatigue in rugby sevens players. Asian journal of sports medicine, 3(3), 175. https://doi.org/10.5812/asjsm.34688

Fisher, J. P. (2014). Autonomic control of the heart during exercise in humans: role of skeletal muscle afferents. Exp Physiol, 99(2), 300-305. https://doi.org/10.1113/expphysiol.2013.074377

Fisher, J. P., Adlan, A. M., Shantsila, A., Secher, J. F., Sørensen, H., \& Secher, N. H. (2013). Muscle metaboreflex and autonomic regulation of heart rate in humans. The Journal of physiology, 591(15), 3777-3788. https://doi.org/10.1113/jphysiol.2013.254722

Fisher, J. P., Young, C. N., \& Fadel, P. J. (2011). Autonomic adjustments to exercise in humans. Compr Physiol, 5(2), 475-512.

Gladwell, V. F., \& Coote, J. H. (2002). Heart rate at the onset of muscle contraction and during passive muscle stretch in humans: a role for mechanoreceptors. The Journal of physiology, 540(3), 10951102. https://doi.org/10.1113/jphysiol.2001.013486

Goldberger, J. J., Le, F. K., Lahiri, M., Kannankeril, P. J., Ng, J., \& Kadish, A. H. (2006). Assessment of parasympathetic reactivation after exercise. Am J Physiol-Heart C, 290(6), H2446-H2452. https://doi.org/10.1152/ajpheart.01118.2005

Goldsmith, R. L., Bloomfield, D. M., \& Rosenwinkel, E. T. (2000). Exercise and autonomic function. Coronary Artery Dis, 11(2), 129-135. https://doi.org/10.1097/00019501-200003000-00007

Gregoire, J., Tuck, S., Hughson, R. L., \& Yamamoto, Y. (1996). Heart rate variability at rest and exercise: influence of age, gender, and physical training. Can J Appl Physiol, 21(6), 455-470. https://doi.org/10.1139/h96-040

Higham, D. G., Pyne, D. B., Anson, J. M., \& Eddy, A. (2012). Movement patterns in rugby sevens: effects of tournament level, fatigue and substitute players. J Sci Med Sport, 15(3), 277-282. https://doi.org/10.1016/j.jsams.2011.11.256

lellamo, F., Legramante, J. M., Pigozzi, F., Spataro, A., Norbiato, G., Lucini, D., \& Pagani, M. (2002). Conversion from vagal to sympathetic predominance with strenuous training in high-performance $\begin{array}{llll}\text { world class athletes. } & \text { Circulation, } & \text { 105(23), } & \end{array}$ https://doi.org/10.1161/01.cir.0000018124.01299.ae

J Henderson, M., K Harries, S., Poulos, N., Fransen, J., \& J Coutts, A. (2018). Rugby sevens match demands and measurement of performance: a review. Kinesiology: International journal of fundamental and applied kinesiology, 50(Supplement 1), 49-59. https://doi.org/10.1080/24733938.2019.1609070

Low P (2001). Fisiología del sistema nervioso autónomo. Medwave, Apr 1;1(4). https://doi.org/10.5867/medwave.2001.04.3347

Matsukawa, K. A. N. J. I., Wall, P. T., Wilson, L. B., \& Mitchell, J. H. (1994). Reflex stimulation of cardiac sympathetic nerve activity during static muscle contraction in cats. Am J Physiol-Heart C, 267(2), H821-H827. https://doi.org/10.1152/ajpheart.1994.267.2.h821

Morales, A. P., Sampaio-Jorge, F., Rangel, L. F. C., Coe1ho, G. M. O., Leite, T. C., \& Ribeiro, B. G. (2014). Heart rate variability responses in vertical jump performance of basketball players. Int $J$ Sports Sci, 4, 72-78. https://doi.org/10.5923/j.sports.20140402.06 
Murata, J., \& Matsukawa, K. (2001). Cardiac vagal and sympathetic efferent discharges are differentially modified by stretch of skeletal muscle. Am J Physiol-Heart C, 280(1), H237-H245. https://doi.org/10.1152/ajpheart.2001.280.1.h237

Povea, C. (2006). Analisis espectral del ritmo cardiaco, utilidad en el deporte. Acta Colombiana de Medicina de Deporte, 12(2), 3-15.

Ravé, J. M. G., Valdivieso, F. N., Fernández, M. D., \& García, J. M. G. (2010). Fundamentos del entrenamiento deportivo. Wanceulen SL.

Rodríguez, F., García, S., Barraza, F., Cabrera, C., \& Siviero, E. (2008). Variables antropométricas y su relación con el rendimiento físico en jugadores de rugby. Rev EFdeportes. Año 13-N 127-Diciembre 2008.

Suarez-Arrones, L. J., Nuñez, F. J., Portillo, J., \& Mendez-Villanueva, A. (2012). Running demands and heart rate responses in men rugby sevens. J Strength Cond Res, 26(11), 3155-3159. https://doi.org/10.1519/jsc.0b013e318243fff7

Takahashi, I., Umeda, T., Mashiko, T., Chinda, D., Oyama, T., Sugawara, K., \& Nakaji, S. (2007). Effects of rugby sevens matches on human neutrophil-related non-specific immunity. Brit J Sport Med, 41(1), 13-18. https://doi.org/10.1136/bjsm.2006.027888

Teixeira, A. L., Daher, M., Souza, M. C., Ramos, P. S., Fisher, J. P., \& Vianna, L. C. (2017). Sympathetically mediated cardiac responses to isolated muscle metaboreflex activation following exercise are modulated by body position in humans. Am J Physiol-Heart C, 314(3), H593-H602. https://doi.org/10.1152/aipheart.00576.2017

Twist, C., \& Highton, J. (2013). Monitoring fatigue and recovery in rugby league players. Int J Sport Physiol, 8(5), 467-474. https://doi.org/10.1123/ijspp.8.5.467

Twist, C., Waldron, M., Highton, J., Burt, D., \& Daniels, M. (2012). Neuromuscular, biochemical and perceptual post-match fatigue in professional rugby league forwards and backs. J Sport Sci, 30(4), 359-367. https://doi.org/10.1080/02640414.2011.640707

West, D. J., Cook, C. J., Stokes, K. A., Atkinson, P., Drawer, S., Bracken, R. M., \& Kilduff, L. P. (2014). Profiling the time-course changes in neuromuscular function and muscle damage over two consecutive tournament stages in elite rugby sevens players. J Sci Med Sport, 17(6), 688-692. https://doi.org/10.1016/j.jsams.2013.11.003

\section{(9) $\mathbb{P} \Theta \Theta$}

This work is licensed under a Attribution-NonCommercial-NoDerivatives 4.0 International (CC BY-NC-ND 4.0). 